\title{
PEMBUATAN SEDIAAN OLES EKSTRAK KENTAL DAUN BINAHONG (Anrederacordifolia (Ten.) Steenis) DAN MADU SEBAGAI PERAWATAN LUKA LUAR
}

\author{
Desri Herawati ${ }^{1}$, Risa Kota Putra ${ }^{2}$, Farhan $^{3}$ \\ ${ }^{1,2,3}$ Sekolah Tinggi Ilmu Kesehatan Holistik Purwakarta
}

\begin{abstract}
ABSTRAK
Latar belakang : Seluruh bagian tanaman Binahong (Anredera cordifolia (Ten.) Steenis) mulai dari akar, umbi, batang, daun dan bunga sangat mujarab untuk terapi herbal. Salah satu khasiat tanaman Binahong (Anredera cordifolia (Ten.) Steenis) yaitu sebagai penyembuhan luka terbuka terutama pada bagian daunnya. Tujuan: Penelitian ini bertujuan membuat sediaan ekstrak kental dari campuran antara daun binahong dan madu untuk perawatan luka luar.

Metode: Metode penelitian ini adalah dekskriptif kualitatif yang dikembangkan dari penelitian sebelumnya mengenai khasiat daun Binahong (Anredera cordifolia (Ten.) Steenis) untuk penyembuhan luka terbuka pada kulit Kelinci. Dalam penelitian ini, sediaan dibuat dari daun Binahong dalam bentuk ekstrak kental yang dicampur dengan madu untuk perawatan luka pada kulit melalui proses sokletasi selama tiga hari dengan menggunakan pelarut Etanol 96\%. Ekstrak dibuat dengan mengekstraksi 50 gr daun binahong dengan $500 \mathrm{~mL}$ Etanol 96\%, ekstrak cair yang dihasilkan kemudian diuapkan, dan diperoleh rendemen sebanyak 24,29\%, lalu ditambahkan $38 \mathrm{~mL}$ madu kedalam 12,145 gr ekstrak kental, sediaan setiap kemasan mengandung 2,46 gr ekstrak kental daun Binahong dan 7,70 mL madu.

Hasil: Sediaan oles ekstrak kental daun binahong dengan madu tahan selama 3 minggu berdasarkan uji organoleptis yang meliputi bentuk, warna, bau, rasa maupun pertumbuhan jamur.
\end{abstract}

Simpulan: Sediaan campuran ekstrak kental dari daun binahong dan madu dapat bertahan selama 3 minggu.

Kata Kunci: Daun binahong, madu, perawatan luka

Korespondensi :

Risa Kota Putra

Program Studi D3 Farmasi, STIKes Holistik Purwakarta

J1. Veteran No.272 Ciseureuh Purwakarta, Jawa Barat 41118

Email :risakotaputra@yahoo.co.id

Phone : 0813-8162-2012 


\title{
MAKING PHARMACETICAL STOCK CONDENSED EXTRACT BINAHONG(Anredera cordifolia (Ten.) Steenis) LEAVES AND HONEY FOR WOUND TREATMENT ON SKIN
}

\begin{abstract}
Backgroud: All parts of the Binahong plant (Anredera cordifolia (Ten.) Steenis) from the roots, tubers, stems, leaves and flowers are very effective for herbal therapy. Especially of the leaves Binahong plant (Anredera cordifolia (Ten.) Steenis) can used to treatment of open wounds.

The aim: This study aims to provide from pharmacetical stock to traditional herb that can be used to prevent a disease and to improve health by community by society.

Method: This research is descriptive method developed from the previous research studied about the efficacy of Binahong leaves (Bassela rubra linn, or Heartleaf maderavine madevine) for curing wound on skin. In this study, the researcher provide pharmacetical stock of Binahong leaves in condensed extract form mixed with honey as wound treatment on skin. The process of pharmacetical stock used soxhlet method, extraction with organic solvents is done repeatedly and keeping constant the amount of solvent, and calculate the yield for three days. The solution used in this process is Ethanol $96 \%$ with $500 \mathrm{cc}$. The solution extract got from this process is $400 \mathrm{cc}$ with yield $24.29 \%$. The making of pharmacetical stock was done by adding $28 \mathrm{cc}$ honey to $12.145 \mathrm{gr}$ condenced extract. Then, the mixture is polished. Next process, the pharmacetical stocks are divided into four pot with each pot is 15 gr. The content of the pharmacetical stock of each pot is 2,46 gr condenced extract of the Binahong leaves and $7.7 \mathrm{cc}$ honey.

Result: Organoleptic test is done for three week. The result is there is no negative change happened viewed by form, colour, odour, and tastes and mushroom growt as well.

Conclusion: The research successfuly made the pharmacetical stock in condenced extract with expire date for three week.
\end{abstract}

Key words: Binahong leaves, Honey, Skin. 
PENDAHULUAN

Tanaman Binahong (Anredera cordifolia (Ten.) Steenis) adalah tanaman asli Paraguay hingga Brazil Selatan dan Argentina Utara. Seluruh bagian tanaman Binahong (Anredera cordifolia (Ten.) Steenis) mulai dari akar, umbi, batang, daun dan bunga sangat mujarab untuk terapi herbal. ${ }^{1}$ Salah satu khasiat tanaman Binahong (Anredera cordifolia (Ten.) Steenis) yaitu sebagai penyembuhan luka terbuka terutama pada bagian daunnya. Kandungan asam askorbat dan saponin pada tanaman ini penting untuk mengaktifkan enzim prolil hidroksilase yang menunjang tahap hidroksilasi dalam pembentukan kolagen, sehingga dapat mempercepat proses penyembuhan luka ${ }^{2}$.

Penelitian mengenai khasiat daun Binahong (Anredera cordifolia (Ten.) Steenis) dalam penyembuhan luka terbuka telah dilakukan terhadap kulit kelinci. Pada penelitian tersebut pembentukan jaringan granulasi dan repitelisasi penyembuhan luka terbuka kulit kelinci dilakukan secara makroskopik dan mikroskopik. Penyembuhan luka pada kulit kelinci terlihat sangat jelas secara makroskopik dan mikroskopik pada hari ke-14, bahwa luka kulit yang diobati dengan lima lembar daun Binahong (Anredera cordifolia (Ten.) Steenis) yang ditumbuk halus terlihat telah kering dan luka tersebut berukuran jauh lebih kecil. Pengobatan tersebut dilakukan sebanyak dua kali sehari, yaitu pagi dan sore ${ }^{3}$.

$$
\text { Penelitian mengenai }
$$
pembuatan sediaan dari daun Binahong (Anredera cordifolia (Ten.) Steenis) yang telah dilakukan diantaranya dalam bentuk sediaan salep yang berkhasiat sebagai penyembuh luka infeksi bakteri Staphylococcus aureus dan dalam bentuk gel sebagai penyembuh luka bakar pada Kelinci. Adapun sediaan dari daun Binahong (Anredera cordifolia (Ten.) Steenis) yang telah beredar dipasaran diantaranya adalah sabun antiseptik, sabun wajah (jerawat), kapsul ekstrak Binahong (Anredera cordifolia (Ten.) Steenis) untuk macam-macam penyakit diantaranya pegal linu, rematik dan penyembuhan luka pasca operasi. Sementara teh celup eksrak Binahong (Anredera cordifolia 
(Ten.) Steenis) untuk penyembuhan luka dalam dan pasca operasi, serta permen yang diperuntukan untuk orang dewasa kisaran umur 20 tahun ke atas untuk pencegahan diabetes dan asam urat. ${ }^{4}$

Penelitian sebelumnya belum ada peneliti yang membuat sediaan daun Binahong (Anredera cordifolia (Ten.) Steenis) yang dicampurkan dengan madu sebagai sediaan oles untuk luka terbuka, maka penulis tertarik untuk membuat sediaan dengan mengkombinasikan daun Binahong (Anredera cordifolia (Ten.) Steenis) dalam bentuk ekstrak kental dengan madu. Penambahan madu dalam pembuatan sediaan ini, dimaksudkan agar sediaan lebih homogen karena tekstur dari madu sendiri yang kental sedikit cair jadi dapat mempermudah pencampuran dan sebagai zat pengawet alami disamping itu juga dapat memperkuat khasiat perawatan luka dari sediaan yang dibuat. Khasiat madu sebagai penyembuh luka berdasarkan penelitian didapatkan adanya perubahan yang baik pada luka yang diberi madu alami ${ }^{5}$ serta madu sering digunakan oleh nenek moyang untuk menyembuhkan berbagai macam penyakit sejak ribuan tahun yang lalu. Madu mengandung senyawa radikal hidrogen peroksida $\left(\mathrm{H}_{2} \mathrm{O}_{2}\right)$ yang bersifat dapat membunuh mikroorganisme patogen, juga adanya senyawa organik yang bersifat antibakteri antara lain polifenol, flavonoid, dan glikosida. ${ }^{6}$

\section{METODE PENELITIAN}

Penelitian ini menggunakan metode penelitian deskriptif kualitatif yang dikembangkan dari penelitian sebelumnya mengenai khasiat daun Binahong (Anredera cordifolia (Ten.) Steenis) untuk penyembuhan luka terbuka pada kulit Kelinci. Pada penelitian ini, peneliti membuat suatu sediaan ramuan tradisional yang dicampur dengan madu berkhasiat untuk perawatan luka luar dalam bentuk ekstrak kental dengan proses ekstraksi menggunakan sokhlet. Instrumen penelitian yang digunakan yaitu studi literatur dan mengkaji jurnal terkait khasiat daun Binahong untuk penyembuhan luka terbuka. 
Daun Binahong (Anredera cordifolia (Ten.) Steenis) dipetik satu persatu dari jenis tumbuhannya yang merambat. Daun Binahong (Anredera cordifolia (Ten.) Steenis) yang dipetik merupakan daun yang berwarna hijau tua dan tebal, yang menandakan bahwa daun tersebut sudah cukup tua untuk dipetik.

\section{Daun Binahong (Anredera} cordifolia (Ten.) Steenis) yang telah dipetik lalu dibersihkan dengan cara mencucinya, pastikan bahwa debudebu dan kotoran yang menempel pada daun tersebut benar-benar bersih. Daun Binahong (Anredera cordifolia(Ten.) Steenis) yang telah bersih kemudian ditiriskan dalam ayakan dari anyaman agar airnya dapat menetes keluar dan dianginanginkan, kemudian daun binahong dikeringkan dalam oven pada suhu $70^{\circ} \mathrm{C}$ selama \pm 5 jam, daun yang telah kering kemudian didinginkan lalu diremas-remas dengan menggunakan tangan sampai terlihat halus. Daun Binahong (Anredera cordifolia (Ten.) Steenis) yang telah diremas lalu disimpan dalam toples yang kering dan bersih serta ditambahkan silika gel yang di simpan didalam toples.

\section{HASIL PENELITIAN}

\section{Persentase Rendemen Simplisia}

Persentase rendemen simplisia daun Binahong (Anredera cordifolia (Tenore.) Steenis) yang dihasilkan dapat dilihat pada Tabel 1 di bawah ini :

Tabel 1. Persen rendemen simplisia

\begin{tabular}{ccc}
\hline Daun Binahong & Simplisia & Rendemen \\
\hline $\mathbf{3 , 5}$ kg & 190,28 gr & $5,44 \%$ \\
\hline
\end{tabular}

Berdasarkan Tabel 1 di atas, diperoleh data bahwa persen rendemen simplisia, daun Binahong (Anredera cordifolia (Tenore.) Steenis) segar ditimbang dengan berat $3,5 \mathrm{~kg}$, menghasilkan berat simplisia sebesar 190,28 gr dengan persentase rendemen yang dihasilkan sebesar $5,44 \%$. 
Persentase Rendemen Ekstrak (Tenore.) Steenis) yang dihasilkan Kental

Persentase rendemen ekstrak kental dapat dilihat pada Tabel 2 di bawah daun Binahong (Anredera cordifolia

Tabel 2. Persen rendemen ekstrak kental

\begin{tabular}{ccc}
\hline Ekstrak cair & Ekstrak kental & $\begin{array}{c}\text { Rendemen } \\
(\mathbf{b} / \mathbf{v})\end{array}$ \\
\hline $\mathbf{4 0 0} \mathbf{~ m L}$ & $12,145 \mathrm{gr}$ & $3,04 \%$ \\
\hline
\end{tabular}

Tabel 2 di atas menunjukkan persentase rendemen ekstrak kental yang diperoleh dari ekstrak cair awal hasil sokhletasi sebanyak $400 \mathrm{~mL}$ dengan ekstraks kentalnya sebanyak 12,145 gr yaitu sebesar $3,04 \%(\mathrm{~b} / \mathrm{v})$.

\section{Berat Sediaan Satu Pot}

Adapun berat sediaan ekstrak kental daun Binahong (Anredera cordifolia (Tenore.) Steenis) dan Madu dalam kemasan satu pot dapat dilihat pada Tabel 3 berikut ini:

Tabel 3. Komposisi Sediaan

\begin{tabular}{ccc}
\hline $\begin{array}{c}\text { Berat Ekstrak } \\
\text { Binahong }\end{array}$ & Volume madu & 1 Pot \\
\hline $\mathbf{2 , 4 6}$ gr & $38 \mathrm{~mL}$ & $15 \mathrm{gr}$ \\
\hline
\end{tabular}

Tabel 3 diatas menunjukkan komposisi sediaan dalam satu pot dengan berat masing-masing bahan yaitu 2,46 gr ekstrak Binahong (Anredera cordifolia (Tenore.)

\section{Dosis Yang Digunakan}

1) JumLah $1 x$ dosis pada ekstrak kental daun Binahong adalah 0,325 gr

Steenis) dan 7,70 $\mathrm{mL}$ madu dengan berat total dalam satu pot yaitu 15 gr.
2) JumLah penambahan madu dalam ekstrak kental adalah sebanyak $38 \mathrm{~mL}$ 


\section{Ekstrak kental}

Ekstrak kental yang

dihasilkan dalam penelitian ini dalam

dilihat pada Tabel 4 di bawah ini :

Tabel 4. Hasil ekstrak kental daun Binahong dicampur Madu

\section{Bentuk sediaan yang diperoleh}

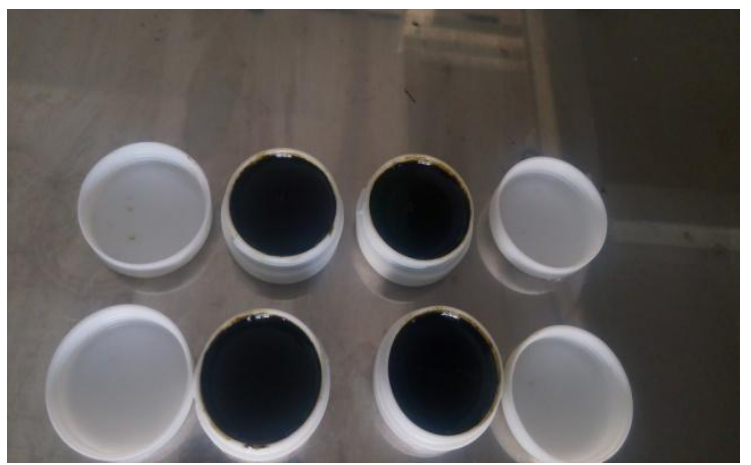

Ciri-ciri Organoleptis

\begin{tabular}{ccccc}
\hline Bentuk & Warna & Bau & Rasa & Jamur \\
\hline $\begin{array}{c}\text { Kental } \\
\text { sedikit } \\
\text { cair }\end{array}$ & Hijau Pekat & Bau khas & Sedikit & Tidak \\
& & daun & manis & tumbuh \\
& & Binahong & & jamur \\
\hline
\end{tabular}

1) Hasil ekstrak kental yang didapat yaitu sebanyak 12,145 gr yang

2) dihasilkan dari 50 gr simplisia kering yang disokletasi atau dari $400 \mathrm{~mL}$ hasil proses ekstraksi soklet (ekstrak cair).
3) Hasil ekstrak kental yang dicampur dengan madu yaitu sebanyak 73,919 gr

4) Berat sediaan akhir satu pot adalah 15 gr yang mengandung ekstrak kental daun Binahong 2,46 gr dan madu 7,70 mL. 
PEMBAHASAN

Daun Binahong (Anredera cordifolia (Tenore.) Steenis) yang digunakan diperoleh dari beberapa tempat, yaitu dari desa Jatiluhur, desa Tegal Munjul, desa Ciwareng dan desa Pasawahan. Daun Binahong (Anredera cordifolia (Tenore.) Steenis) dipetik dari ketinggiannya \pm 1200 meter diatas permukaan laut. Pengumpulan daun Binahong (Anredera cordifolia (Tenore.) Steenis) dengan ukuran yang sama sulit didapatkan karena sampel diambil dari beberapa tempat, sehingga terdapat beberapa ukuran daun yang kecil dan lebar. Daun Binahong (Anredera cordifolia (Tenore.) Steenis) yang dikumpulkan atau dipetik yaitu daun yang berwarna hijau tua. Ukuran daun yang berbeda-beda dapat dikarenakan oleh perbedaan cara tanamnya, yaitu ada yang sengaja menanam sebagai tanaman obat dengan menanamnya didekat ternak ayam yang tidak terkena cahaya matahari langsung atau sedikit sejuk, sehingga daunnya tumbuh lebih besar dan subur, ada pula yang ditanam begitu saja sehingga bercampur dengan rumput liar, dengan hasil daun berukuran lebih kecil. Kekurangan lain dalam pengumpulan daun, seharusnya dilakukan pada satu tempat untuk memaksimalkan hasil yang didapat baik dari khasiat ataupun jumlah kandungan kimia yang dimiliki.

Daun Binahong (Anredera cordifolia (Tenore.) Steenis) yang telah dikumpulkan lalu melalui tahap pengolahan lanjut yaitu: pembersihan daun dari pengotornya, pencucian, penirisan dan kemudian pengeringan. Daun dikeringkan dengan menggunakan oven, agar proses pengeringan tidak menghabiskan waktu yang lama karena tekstur dari daun Binahong (Anredera cordifolia (Tenore.) Steenis) itu sendiri merupakan daun yang cukup tebal. Pengeringan ini bertujuan untuk meningkatkan daya tahan simplisia sehingga dapat disimpan dalam jangka waktu yang lama. Dengan metode yang dilakukan ini diperkirakan ada degradasi zat berkhasiatnya. Berat daun Binahong sebelum dikeringkan yaitu $3,5 \mathrm{~kg}$ sedangkan setelah pengeringan diperoleh 190,28 gr dengan persentase rendemen simplisianya sebesar 5,44\%. Setelah kering, 
simplisia ini kemudian dihaluskan hingga berbentuk serbuk, tujuannya untuk mempermudah pelaksanaan tahapan selanjutnya yaitu proses ekstraksi.

Metode ekstraksi yang digunakan pada penelitian ini adalah sokhletasi dengan menggunakan pelarut Etanol 96\%. Prinsip sokletasi ini yaitu penyaringan yang dilakukan secara berulang-ulang sehingga hasil yang didapat sempurna dan pelarut yang digunakan relatif sedikit. Metode sokletasi menggunakan suatu pelarut yang mudah menguap dan dapat melarutkan senyawa organik yang terdapat pada bahan tersebut, tapi tidak melarutkan zat padat yang tidak diinginkan, ${ }^{7}$ maka dari itu dalam proses sokhletasi ini peneliti menggunakan pelarut Etanol $96 \%$. Metode Sokletasi ini dapat digunakan pula pada sampel dengan tekstur yang lunak dan tahan pemanasan sehingga diharapkan kandungan kimia yang diinginkan keluar secara sempurna begitu juga cairan zat terekstrak yang didapat lebih baik dalam penyimpanan dengan waktu yang lama. Pelarut etanol $96 \%$ dipilih menjadi pelarut dalam proses sokletasi ini karena etanol 96\% merupakan pelarut yang universal yang dapat melarutkan senyawa polar maupun nonpolar sehingga diharapkan dengan menggunakan pelarut etanol $96 \%$ zat aktif yang diperlukan dapat tertarik sepenuhnya. Pada penelitian ini diekstraksi sebanyak 50 gr simplisia daun Binahong (Anredera cordifolia (Tenore.) Steenis) dan menghasilkan 400 mL ekstrak cair.

Pembuatan ekstrak kental dilakukan dengan cara penguapan menggunakan penangas air. Cawan penguap yang digunakan yaitu dengan menggunakan beberapa cawan untuk memperoleh hasil ekstrak kental dalam waktu yang tidak terlalu lama. Tetapi, sebaiknya cawan yang digunakan cukup satu cawan, dengan selalu menambahkan ekstrak cair sedikit demi sedikit ke dalam cawan setiap cairan tersebut telah mengental menjadi sepertiganya, sehingga dapat menghasilkan ekstrak kental dengan berat yang lebih stabil.

Hasil ekstrak kental yang didapat yaitu sebanyak 12,145 gr dari 400 mL ekstrak cair (50 gr simplisia) 
dengan persentase rendemen ekstrak kental yang diperoleh yaitu sebesar $3,04 \%(\mathrm{~b} / \mathrm{v})$.

Pembuatan sediaan yang dilakukan yaitu penambahan ekstrak kental Daun Binahong (Anredera cordifolia (Tenore.) Steenis) dengan madu. Di zaman Yunani dan Mesir kuno, madu sering digunakan untuk mengawetkan daging sehingga hasilnya masih tetap segar setelah beberapa minggu disimpan. Selain itu madu sudah dimanfaatkan untuk mengobati luka bakar dan luka akibat benda tajam. Sifat antibakteri dari madu membantu mengatasi infeksi pada luka ${ }^{6}$ Dalam hal ini, peneliti melakukan penambahan madu dalam pembuatan ekstrak kental dengan tujuan sebagai zat pengawet alami, disamping juga dapat memperkuat khasiat sebagai perawatan luka. Berat total sediaan ekstrak kental yang dicampur dengan madu yaitu sebanyak 73,919 gr. Berat masingmasing sediaan tiap 1 pot yaitu sebanyak 15 gr mengandung 2,46 gr ekstrak kental dan 7,70 mL madu. Bentuk sediaan dari ekstrak kental daun Binahong (Anredera cordifolia (Tenore.) Steenis) yang dicampur dengan madu ini sedikit cair, diperkirakan karena madu yang digunakan yaitu madu dengan kekentalan yang tidak terlalu pekat.

Pengujian organoleptis sediaan selama 3 minggu merupakan tahap selanjutnya, dengan tujuan untuk menguji kestabilan sediaan dan memastikan tidak terjadinya perubahan bentuk, warna, bau, rasa maupun tumbuhnya jamur didalamnya. Pengujian dilakukan dengan menyimpan sediaan dalam dua tempat dengan suhu yang berbeda, yaitu di dalam lemari pendingin dengan suhu $10^{\circ} \mathrm{C}$ dan di dalam kamar dengan suhu ruangan yaitu $25^{\circ} \mathrm{C}$. Hasil yang didapat selama tiga minggu menunjukan bahwa tidak ada perubahan dalam hal bentuk, warna, bau, rasa maupun tumbuhnya jamur pada sediaan tersebut diperkirakan karena adanya madu dalam sediaan sebagai bahan pengawet alami dan karena proses pemanasan yang stabil, sehingga dapat dikatakan bahwa sediaan yang peneliti buat tahan selama tiga minggu. Pengujian organoleptis setelah 3 minggu pun dilakukan oleh peneliti untuk memastikan bahwa sediaan yang dibuat oleh peneliti lulus uji ketahanan sediaan lebih dari 
tiga minggu. Penyimpanan yang disimpan dilemari pendingin, ekstrak kental daun Binahong (Anredera cordifolia (Tenore.) Steenis) dan madu terlihat lebih mengental dibandingkan dengan yang berada di dalam kamar, tetapi dalam penelitian ini tidak dilakukan uji kestabilan bentuk dan khasiat sediaan, maka peneliti pun belum menyatakan penyimpanan yang baik itu disimpan di tempat yang sejuk/dingin agar lebih mengental maupun di dalam suhu kamar dengan kekentalan yang sedikit cair.

Penelitian ini merupakan suatu penelitian pengembangan yang berupa pembuatan sediaan dari bahan herbal yang dapat digunakan sebagai perawatan luka. Bahan herbal yang digunakan yaitu daun Binahong (Anredera cordifolia (Ten.) Steenis) yang dibuat dalam bentuk sediaan oles ekstrak kental dicampur dengan madu sebagai penggunaan luar. Penelitian ini hanya terbatas melakukan pengujian organoleptis terhadap sediaan yang telah dibuat, meliputi pengamatan terhadap bentuk, warna, bau, rasa dan tumbuhnya jamur yang dilakukan selama 3 minggu.

\section{SIMPULAN}

$\begin{array}{rcc}\text { Berdasarkan } & \text { penelitian yang } \\ \text { telah dilakukan terbukti daun }\end{array}$
Binahong (Anredera cordifolia (Ten.) Steenis) berkhasiat untuk penyembuhan luka terbuka dan pada penelitian ini, daun Binahong (Anredera cordifolia (Ten.) Steenis) terbukti dapat diolah menjadi suatu bentuk sediaan yang dapat digunakan untuk perawatan luka luar pada kulit ${ }^{4}$.

Sediaan dari daun Binahong (Anredera cordifolia (Ten.) Steenis) telah berhasil dibuat dalam bentuk ekstrak kental yang dicampur dengan madu dan dapat bertahan selama tiga minggu, tanpa ada perubahan secara dalam bentuk, bau, warna, rasa maupun tumbuhnya jamur dikarenakan penambahan Madu sebagai zat pengawet alami dan juga metode ekstraksi yang digunakan yaitu proses sokletasi yang menggunakan pemanasan secara konstan dan stabil.

\section{SARAN}

Sediaan yang telah dibuat perlu dilakukan penelitian lebih lanjut mengenai pengujian sediaan terhadap luka luar pada kulit maupun 
penelitian untuk memastikan kebenaran dan kestabilan khasiat sediaan serta dalam pengemasan akhir sediaan dapat dikemas dalam bentuk tube untuk kestabilan bentuk sediaan.

\section{DAFTAR PUSTAKA}

1. Manoi, F. Binahong (Anredera cordifolia) Sebagai Obat. Jurnal Warta Penelitian dan Pengembangan Tanaman Industri. 2009;1.15(1): 3-5.

2. Hidayat, I. Uji Aktivitas Salep Ekstrak Daun Binahong (Anredera cordifolia(Ten.)

Steenis) Sebagai Penyembuh Luka Bakar pada Kulit Punggung Kelinci (Skripsi).Surakarta: Fakultas Farmasi Universitas

Muhammadiyah; 2009.

3. Suci, A., Lily, L., Meilany, D. Khasiat Daun Binahong (Anredera cordifolia (Ten.) Steenis) Terhadap Pembentukan jaringan Garanulasi Dan
Reepitelisasi Penyembuhan

Luka Terbuka Kulit Kelinci.

Manado: Fakultas Kedokteran

Universitas Sam Ratulangi; 2012.

4. Pramana, R., Suryani, M., Supriyono, M. Efektifitas Pengobatan Madu Alami Terhadap Penyembuhan Luka Infeksi Kaki Diabetik (IKD). Semarang; 2012.

5. Wakirani, Endah, K. Khasiat Daun Binahong (Anredera cordifolia(Ten.) Steenis) Sebagai Penyembuhan Luka Terbuka". Diunduh dari URL: https://www.academia.edu/1297 0619. Diakses pada 22 Agustus 2016.

6. Pramana, R., Suryani, M., Supriyono, M. Efektifitas Pengobatan Madu Alami Terhadap Penyembuhan Luka Infeksi Kaki Diabetik (IKD). Semarang; 2012.

7. Ikhwan, D., dkk. Praktikum Kimia Organik II. Pontianak: Universitas Tanjungpura; 2012. 